\title{
Corrigendum: Clinical Characteristics and Predictors of Outcome for Onconeural Antibody-Associated Disorders: A Retrospective Analysis
}

\author{
Shaohua Liao 1,2,3t, Ying Qian ${ }^{1,2 t}$, Huaiqiang $\mathrm{Hu}^{2}$, Bing $\mathrm{Niu}^{2}$, Hongwei Guo ${ }^{2}$, \\ Xiaoling Wang ${ }^{2}$, Shuai $\mathrm{Miao}^{2}$, Chuanfen $\mathrm{Li}^{2}$ and Bingzhen $\mathrm{CaO}^{2 *}$ \\ ${ }^{1}$ Department of Neurology, Graduate School of the Second Military Medical University, Shanghai, China, ${ }^{2}$ Department of \\ Neurology, General Hospital of Jinan Military Command of PLA, Jinan, China, ${ }^{3}$ Department of Neurology, People's Liberation \\ Army 152 Hospital, Pingdingshan, China
}

Keywords: onconeural antibody, clinical characteristics, management, outcome, predictors

\section{OPEN ACCESS}

Edited and reviewed by: Sandro M. Krieg, Technische Universität München

Germany

${ }^{*}$ Correspondence: Bingzhen Cao

cbzxia2011@163.com

tThese authors have contributed equally to this work and should be considered co-first authors

Specialty section

This article was submitted to Neuro-Oncology and Neurosurgical Oncology,

a section of the journal Frontiers in Neurology

Received: 06 July 2018

Accepted: 10 August 2018 Published: 05 September 2018

Citation:

Liao S, Qian Y, Hu H, Niu B, Guo H, Wang $X$, Miao $S, L i C$ and $C a O B$ (2018) Corrigendum: Clinical Characteristics and Predictors of Outcome for Onconeural Antibody-Associated Disorders: A

Retrospective Analysis.

Front. Neurol. 9:729.

doi: 10.3389/fneur.2018.00729

\section{A Corrigendum on}

Clinical Characteristics and Predictors of Outcome for Onconeural Antibody-Associated Disorders: A Retrospective Analysis

by Liao S, Qian Y, Hu H, Niu B, Guo H, Wang X, et al. (2017). Front. Neurol. 8:584. doi: 10.3389/fneur.2017.00584

In the original article, there was a mistake in the third last patient in table 1 is listed to have the onconeuronal antibody "Am", which is corrected as "Amphiphysin". The authors apologize for this error and state that this does not change the scientific conclusions of the article in any way.

In addition, there was an error in the conclusion of the abstract, caused by a misunderstanding during the language translation. The original text is:

By contrast, cerebrospinal fluid analysis showed that serum autoantibodies and tumor markers, the function of crucial organs, electrophysiology, and radiological findings were not associated with a poor outcome.

A correction has been made to the corresponding text in the conclusion of the abstract:

By contrast, the results showed that cerebrospinal fluid analysis, serum autoantibodies and tumor markers, the function of crucial organs, electrophysiology, and radiological findings were not associated with a poor outcome.

The authors apologize for this error and state that this does not change the scientific conclusions of the article in any way.

Conflict of Interest Statement: The authors declare that the research was conducted in the absence of any commercial or financial relationships that could be construed as a potential conflict of interest.

Copyright (c) 2018 Liao, Qian, Hu, Niu, Guo, Wang, Miao, Li and Cao. This is an open-access article distributed under the terms of the Creative Commons Attribution License (CC BY). The use, distribution or reproduction in other forums is permitted, provided the original author(s) and the copyright owner(s) are credited and that the original publication in this journal is cited, in accordance with accepted academic practice. No use, distribution or reproduction is permitted which does not comply with these terms. 